\title{
Influence of Institutional Factors On Public Procurement Performance in County Governments in Kenya: A Case of County of Garissa
}

\author{
Mr. Mohammed Abdi Hassan, \\ School of Business and Economics, \\ Mount Kenya University-Thika \\ BOX 174-70100 Garissa \\ Email: akey114@hotmail.com
}

\author{
Dr. Peter Wamalwa Barasa, PhD \\ School of Business and Economics, \\ Mount Kenya University-Thika \\ P.O BOX 42702- 80100, MOMBASA KENYA \\ Email: petbar2001us@yahoo.com \\ DOI: 10.29322/IJSRP.11.10.2021.p11881 \\ http://dx.doi.org/10.29322/IJSRP.11.10.2021.p11881
}

\begin{abstract}
The study aimed at investigating the influence of institutional factors on public procurement performance in the county. The specific objectives of the study was to; establish the influence of Staff Professionalism on procurement performance, to find out the influence of Organizational Culture on procurement performance, examine the influence of Institutional Framework on procurement performance, and determine the influence of Top Management Support on procurement performance in Garissa County. The study was anchored on institutional theory by DiMaggio and Powell (1991), social-economic theory by Sutinen and Kuperan (1999) and Nortel Network External Environment Theory by Nortel (1999). Descriptive research design was used. The target population was all employees in the departments involved in procurement activities, that is the IT department, the Accounts and Finance department as well as the Procurement and Logistics department were also involved in the study. Purposive and simple random sampling techniques were used to select the data. The data in the study was collected through use of a questionnaire which was structured to capture quantitative data. Both descriptive and inferential statistics were to be used to analyze the data. The results indicated that staff professionalism and procurement performance were positively correlated, $r(90)=.84, p=.00$. Organizational culture influence and procurement performance had a significant and positive correlation $r(90)=.51, p=.00$. Institutional framework and procurement performance had a significant and positive correlation $r(90)=.77, p=.00$. Top management and procurement performance are positively correlated, $r(90)=.87, p=.00$. Based on the results, the study recommends that county governments should put in place measures to enhance staff professionalism, organizational culture, top management support and institutional framework for better performance in the procurement sector. More focus should be given to the management as the focal point in enhancing procurement performance. The study recommends that motivation and rewards to employees should be enhanced in order to improve their capacity while giving them the flexibility they need to grow and function in their respective dockets in the procurement department.
\end{abstract}

\subsection{Introduction}

Public finance management aims to reduce procurement costs as well as enhance efficiency in the public sector (World Bank, 2020). This troubles the public sector across the developed and developing countries. As a result, the countries have embarked on reforms and restructuring of their rules and regulations in order to improve public procurement performance (Nyoike, 2019). Among the institutions and other agents in the public sector, procurement is shrewd with malpractices leading to losses (Mutangili, 2019). The need to have public procurement legislation was necessitated because of several reported malpractices in most government entities 
(Amemba, Nyaboke, Osoro \& Mburu, 2013). Any government department that does not fully implement the Public Procurement legislation cannot attain optimal customer satisfaction and thus it is not able to deliver the required level of service to the public (Amayi \& Ngugi, 2013).

Onyango(2020) indicated that due to poor procurement structures and policies, lots of public money has been wasted. In the modern world, public procurement has been so critical that it has attracted attention and debate as well as led to enactment of reforms and rules to reorganize it (World Bank, 2020). Public procurement has been shrouded in myriad malpractices in the procurement processes. It is argued that engaging in public procurement has become the biggest earner for corrupt politicians, vendors, civil servants and other stakeholders who get involved (Manyenze, 2013). Vilcu et al. (2020) demonstrated that through inefficient procurement methods, failure to strictly impose sanctions and non-compliance to procurement regulations, public financial resources get wasted.

The problem of procurement performance in the public sector is not Kenyan problem only. Bosio et, al. (2018) argued that poorly coordinated procurement activities, lack of compliance to procurement laws and regulations and ineffective structures greatly affect performance of organizations in both the private and public sector. In the UK and European countries, cases of malpractices in procurement activities are not rampant because of well-established regulations and structures (Jefferson, 2013) but also Fazekas and Kocsis (2018) indicated that it's not just in the developing countries that procurement activities are marred by corruption but also in the developed economies as well. Taking the case of Malaysia, Hui et al (2011) agreed that procurement malpractices exist and that most to blame were the procurement officers involved in the activities.

Sun \& Sales (2018) indicated and acknowledged the importance of reforms in procurement activities in the developing economies in Africa. Kakwezi and Nyeko (2013) argued that Uganda had made strides in its efforts of reforming procurement regulations due to both internal and external pressure since the government had been incurring massive losses which cost the taxpayer a lot of money. In South Africa, the past government procurement activities were biased towards the small contractors and were marred by corruption cases. There have since been reforms of the same to make it a constitutional right for everyone regardless of the status to do business with the government (Gorsira, et al., 2018).

In Kenya, there had been massive changes to the procurement activities in the procurement systems. Previously, the sector was unregulated in the 60s but since the 70s to $90 \mathrm{~s}$, the system started being regulated by circulars before enactment of the procurement regulations in the year 2019 as argued by (Matano et al., 2018). Before enactment of the procurement regulations, Broms, Dahlstrom and Fazekas (2019) indicated that the new government of Kibaki conducted a review of the existing procurement systems and revealed massive loopholes which necessitated enactment of procurement legislations. Previously, there was no disciplinary action against those who either broke the rules or breached procurement contracts, other than internal disciplinary actions. In the year 2005, there was a review of the procurement systems which was done by the joint efforts of the Kenyan government and the European Union. The review established among others, weak institutional frameworks, poor linkages of procurement activities, less transparency as well as inefficiencies caused by among other factors, lack of effective records management practices. As a result, the government focused on coming up with the Public Procurement and Disposal Act and an oversight authority, Public Procurement Oversight Authority (PPOA) to ensure efficiency in procurement activities (Otieno, 2015). PPOA had been mandated to audit procurement contracts and monitor procurement activities and systems in the public sector and report on its functioning. The same derived its powers from the PPDA Act (2005) (Edward, 2011). Due to inherent challenges, the Act was amended to PPADA 2015. Despite these reforms, public procurement in the public sector still faced challenges (Mwangi, 2020). This led to issues of mismanagement of public funds in the process of procurement of goods and services.

\section{Specific Objectives of the Study}

i. To establish the influence of Staff Professionalism on Public procurement performance in County Governments in Kenya ii. To determine the influence of Organizational Culture on Public procurement performance in County Governments in Kenya

iii. To examine the influence of Institutional Framework on Public procurement performance in County Governments in Kenya

iv. To determine the influence of Top Management Support on Public procurement performance in County Governments in Kenya

\subsection{Literature Review}


The study was anchored on institutional theory by DiMaggio and Powell (1991), social-economic theory by Sutinen and Kuperan (1999) and Network External Environment Theory by Nortel (1999).

\section{Conceptual Frame work}

The study investigated whether Staff professionalism, Organizational culture, Institutional framework and top management support influence procurement performance. In this case, manipulation of any independent variable was expected to affect procurement performance either in a positive or negative way. Figure 1 indicates the relationship between the variables.

\section{Figure 1 Conceptual Framework}

Independent Variables

\begin{tabular}{|c|}
\hline Staff Professionalism \\
Ethical values \\
Professional qualifications \\
Academic qualifications \\
\hline Organizational Culture \\
Work ethics \\
Work Values \\
Team work \\
\hline
\end{tabular}

Institutional Framework Centralization of

decisions

Internal Procedures

Bureaucratic structure

decisions
Internal Procedures
Bureaucratic structure

\section{Dependent variable}

Top Man agement Support

Financial support

Political goodwill

Supportive policies

Source: Researcher, (2021)

\section{Influence of Staff Professionalism on Public Procurement Performance in County Governments in Kenya}

Larbi, Baiden and Agyekum (2019) interrogated the extent of compliance to procurement legislations in Ghana. It was a descriptive study and hence the tools for data collection were questionnaires. Data analysis indicated absence of professionalism in the procurement process at the Ashanti Region of Ghana. Onyinkwa (2014) Investigated whether staff professionalism was critical in conducting procurement activities among secondary schools in Kisii county. Through the use of questionnaires, it was established that professionalism was evident in the process adopted by the schools in procuring and hence it was determined to be a critical factor.

In another context, Ngugi and Mugo, Toroitich, Mburugu and Waweru (2017) focused on the procurement process at the national level and established whether there was accountability and professionalism at the Ministries department of finance and procurement. Using primary data and inferential statistics, it was indeed shown that such factors were available and critical.

\section{Influence of Organizational Culture on Public Procurement Performance in County Governments in Kenya}

Muya et al. (2012) interrogated the organizational culture in state corporations and how it was important to procurement. In so doing, structured questionnaires collected primary data which was analyzed through correlation analysis. The study showed that even though there was high resistance to change in the organizations, the success of procurement heavily relied on it. Focusing on the state law office, Ikumu, Iravo and Ondabu (2014), aimed to establish what critical factors determined the procurement process in the public 
ISSN 2250-3153

sector. A number of factors were established after interviews were conducted and thematically analyzed. Apart from other factors such as IT and professionalism, organizational culture was also identified to be important.

Hossain (2017) focused on the determinants of procurement process efficiency of British American Tobacco in Bangladesh. The study conducted a case study using quantitative methods and revealed that organizational culture, resources and technology are some of the determinants of procurement process efficiency.

\section{Influence of Institutional Framework on Public Procurement Performance in County Governments in Kenya}

Ombuki, Arasa, Ngugi, and Muhwezi, (2014) sought out the factors that affected compliance to procurement regulations among higher learning institutions in Kenya. Through a descriptive survey, the study mainly ranked top leadership support or political factors as well as the institutional framework as the most important factors. Gatere and Shale (2014) on the other hand investigated the success factors for implementation of the reservations policy among selected public entities in Nairobi County. The procurement staff among those institutions was interviewed and it was established that apart from legal framework, funding, training and availability of information, Institutional framework was also a significant factor.

Thairu and Chirchir (2016) established whether the institutional framework existing among the state-owned enterprises was satisfactory in ensuring adherence to public procurement. After surveying close to 70 organizations, it was indicated that existence of an effective institutional framework was a critical factor in ensuring better procurement performance.

\section{Influence of Top Management Support on Public Procurement Performance in County Governments in Kenya}

Musau (2015) established the environmental factors affecting procurement performance in county governments. The study focused on a case study of Uasin Gishu County in Kenya. A descriptive survey was adopted and data was collected through questionnaires. The study showed that other than the economic and legal environment, the political environment was also an important factor which determined how procurement was conducted in the county governments.

Raslan and Kapogiannis (2018) interrogated whether the integrated collaborative environment affected procurement performance in Saudi Arabia. Collaborative environment included the collaborations between the top management and the subordinates. It was demonstrated that such an arrangement was not exhaustively important but it was critical in ensuring effectiveness in procurement.

A study was conducted by Ashley et al. Kakwezi and Nyeko (2019) to establish success factors for implementation of projects, strategies and programmes in the public sector. Among the key study findings was that political intervention is critical. It was the main issue surrounding successful implementation of plans and projects in the public sector. In another study, (Srivastava and Agrahari (2017) sought to establish the critical success factors for effective procurement performance in the public sector. The study posited that political factors cannot be left out since the whole process is centered on politics.

In another study, Abdumlingo and Mugambi (2014) focused on establishing the challenges in management of devolved funds in the delivery of services in county governments with a focus on Mombasa County. The study findings pointed towards political factors ranging from corruption, policies, transparency and accountability as the main determinants of success in management of the devolved funds.

\subsection{Research Methodology 3.1. Research Design}

It is an arrangement of how data can be collected and analyzed to achieve the objectives (Garg \& Kothari, 2014). The study used descriptive research design. According to Garg and Kothari (2014), a descriptive research design entails collection of data which is then descriptively analyzed to explain a research phenomenon. A descriptive survey design was suitable in this work because it did support the use of questionnaires as well as provide answers to the sort of questions it sought to answer. Furthermore, since the study also had to conduct a census on the entire target population, the most suitable research design would be a descriptive survey. The research design was therefore justified on this ground.

\subsection{Target Population}

A list of elements from which a smaller subset was chosen to participate in the study is a population (Blumberg, Cooper \& Schindler, 2014). The study focused on the Garissa County government. The target population was 107 employees in the Information Technology department, Accounts and Finance department as well as the Procurement and Logistics department. 


\subsection{Sample and Sampling Procedure}

Sampling basically involves coming up with a smaller subset of the target population either scientifically or not scientifically but to ensure that it has similar characteristics as the entire population (Wilson, 2014). The study adopted a census whereby all the 107 units of observation were considered (Zhang, 2009). Blumberg, Cooper and Schindler (2014) argue out that a census approach can be adopted for a population less than 200. A census was most suitable for the study so as to enhance the opinion from the respondents.

Table 1: Sample Size

\begin{tabular}{lc}
\hline Department & Sample \\
\hline Information Technology & 28 \\
Accounts and Finance & 36 \\
Procurement and Logistics & 43 \\
\hline Total & $\mathbf{1 0 7}$ \\
\hline
\end{tabular}

Source: Human Resource Department, Garissa County (2020)

\subsection{Data Collection Method}

Lara-Alecio, Guerrero and Lopez (2019) indicate that it is defined as gathering of research information. The study gave the respondents the questionnaires to fill by themselves. The tool was given out and picked after some time. The respondents were allocated one week to fill the questionnaires. Additional week was allocated to questionnaires that had not been filled.

\subsection{Validity and Reliability of Research Instrument}

Sinha, et al., (2019) define reliability as how consistent an instrument can be in capturing data. The extent to which similar results in similar trials can be obtained refers to reliability. Various methods such as internal consistency (Cronbach Alpha) can be used to determine reliability. This was the approach the study adopted at a threshold of 0.7. A high reliability estimate should be as close to 1 as possible, however, 0.7 was good enough.

When a tool measures what it was initially intended to measure, it is said to be valid (Melanie \& Eriikka, 2013). It is just a relook at the questionnaire to ensure that it reflects the objectives of the study. When establishing validity, focus is normally placed on ensuring that there are no errors or ambiguity (Brace, 2013). Content validity was established when the supervisor gave comments on the questionnaire and advised on its clarity. Based on the supervisor's response, the questionnaire was adjusted accordingly.

\subsection{Presentation of Data and Analysis.}

Smith (2015) argued that data analysis means manipulation of data systematically to make meaningful information out of it. The study used two methods to analyze the quantitative data. Quantitative analysis methods through SPSS version 22 were conducted. Both descriptive and inferential statistics were also conducted. Mean and frequencies as well as percentages were used to describe the population. Correlation and regression was used to establish a relationship between the variables. A multiple regression analysis indicated in the equation was suitable for the study:

$\mathbf{Y}=\boldsymbol{\beta}_{0}+\boldsymbol{\beta}_{1} \mathbf{X}_{1}+\boldsymbol{\beta}_{2} \mathbf{X}_{2}+\boldsymbol{\beta}_{3} \mathbf{X}_{3}+\boldsymbol{\beta}_{4} \mathbf{X}_{4}+\varepsilon$

Where;

$\mathbf{Y}=$ Procurement Performance; $\mathbf{X}_{\mathbf{1}}=$ Staff Professionalism; $\mathbf{X}_{\mathbf{2}}=$ Organizational Culture; $\mathbf{X}_{\mathbf{3}}=$ Institutional Framework; $\mathbf{X}_{\mathbf{4}}=$ Top Management Support; $\varepsilon=$ Error term (Other factors other than the four factors)

$\boldsymbol{\beta}_{0}$ is the regression constant or intercept,

$\boldsymbol{\beta}_{1}, \boldsymbol{\beta}_{2}, \boldsymbol{\beta}_{\mathbf{3}}$ and $\beta_{4}$ are the unknown parameters to be determined.

Before using a linear regression model, the assumptions of classical linear regression were tested. The study also tested for multicollinearity using Variance Inflation Factor to establish whether the independent variables are highly correlated. In this method, a VIF value above 10 indicates presence of multicollinearity. Another assumption of classical linear regression is normality of the variables. This study tested whether the variables have a normal distribution using Kolmogorov Smirnov test. In this test, a significance value above 0.05 shows normality. Additionally the study also tested for linearity to establish whether the relationship between the independent and dependent variables was linear. In this method, scatter plots were adopted. Another assumption was autocorrelation where the variation in the error term was tested. In this method, Breusch Godfrey method was adopted where a p- 
value $>0.05$ indicates presence of serial correlation. The study also tested for homogeneity using Levine's method to establish whether the variation in the error term is constant across the independent variables.

\subsection{Data Analysis and Discussion}

\section{Reliability of the Research Instruments}

The questionnaire that was used consisted of six sections and researcher used the split half technique to test the reliability of the research instrument. Table 2 indicates that the reliability coefficients for all the measures were within the acceptable range. The highest and the lowest values of Cronbach's alpha coefficients were 0.86 and 0.75 respectively. The values were above 0.70 as recommended by Mugenda and Mugenda (2012) for demonstrating the reliability of the research instruments. The aggregate value of Cronbach's alpha coefficient for the study variables was 0.798 . This was also above the recommended 0.70 . Therefore, the research instrument was reliable to be used in this study.

Table 2: Reliability of the Research Instruments

\begin{tabular}{lcc}
\hline Scale & No. Items & Cronbach's alpha \\
\hline Staff Professionalism & 5 & .86 \\
Organizational Culture & 6 & .75 \\
Institutional Framework & 5 & .78 \\
Top Management Support & 5 & .79 \\
Procurement performance & 5 & .81 \\
\hline
\end{tabular}

Source: Researcher, (2021)

\section{Influence of Staff Professionalism on Public Procurement Performance in County Governments in Kenya}

Table 3 presents the descriptive statistics of staff professionalism responses. In the first question, the respondents were asked whether the County Government upholds ethical values among its employees. The results indicated that $10 \%$ of the participants strongly disagreed and 5.6\% disagreed. The findings also indicated that $2.2 \%$ of the participants were undecided while $76.7 \%$ agreed and $5.6 \%$ strongly disagreed. The total mean score was $3.62(S D=1.03)$. The findings show that the participants were certain that the county Government upholds ethical values amongst the staff.

The question regarding whether the procurement professionals meet the educational requirements, the results showed that majority of the respondents (75.7\%) agreed and 7.6 strongly agreed. The findings also indicate that $5.7 \%$ of the participants were undecided while $1.1 \%$ of the respondents disagreed and $1.1 \%$ strongly disagreed. The mean score and standard deviation were 3.67 and 0.98 respectively. Based on these findings, it's clear that the procurement staff meet the stipulated educational requirements.

Regarding whether the procurement staff meet the professional requirements, the findings showed that majority of the participants representing $77 \%$ were undecided, $10 \%$ agreed, $6 \%$ strongly disagreed while $7 \%$ disagreed. The mean score was $2.56(S D=0.98)$. These findings revealed that generally the participants were not sure if the procurement professionals met the professional requirements.

The study also sought to establish if the procurement professionals meet the work experience requirements. The results demonstrated that most of the participants representing $62 \%$ agreed and $12 \%$ strongly agreed. However, the findings also indicated that $16 \%$ were undecided, $2 \%$ disagreed while $8 \%$ strongly disagreed that the professionals did. The mean score was $3.55(S D=1.10)$. Based on the report findings the procurement professional meets the work experience requirements.

The question regarding whether the county upholds virtues of trust and honesty among its employees yielded results indicating that the majority of the participants (46\%) disagreed and 5\% strongly disagreed. The results also revealed that $15 \%$ of the respondents agreed, $10 \%$ strongly agreed while $24 \%$ were undecided. The mean score was 2.21 with a standard deviation of 1.03 . The results showed that generally the county does not uphold virtues of trust and honesty among its employees.

Table 3: Descriptive statistics on Influence of Staff Professionalism on Public Procurement Performance in County Governments in Kenya

\begin{tabular}{llllllll}
\hline Statement & & & & & & \\
& SD & D & N & A & SA & Mean & SD \\
\hline The county upholds ethical values among its employees & $10 \%$ & $5.6 \%$ & $2.2 \%$ & $76.7 \%$ & $5.6 \%$ & 3.62 & 1.03 \\
The procurement professionals meet the educational requirements & $11 \%$ & $1.1 \%$ & $5.7 \%$ & $75.7 \%$ & $7.6 \%$ & 3.67 & 0.98 \\
\hline
\end{tabular}

This publication is licensed under Creative Commons Attribution CC BY. 


\begin{tabular}{|c|c|c|c|c|c|c|c|}
\hline Statement & SD & D & $\mathbf{N}$ & $\mathbf{A}$ & SA & Mean & SD \\
\hline The procurement professionals meet the professional requirements & $6 \%$ & $7 \%$ & $77 \%$ & - & $10 \%$ & 2.56 & 1.02 \\
\hline $\begin{array}{l}\text { The procurement professionals meet the work experience } \\
\text { requirements }\end{array}$ & $8 \%$ & $2 \%$ & $16 \%$ & $62 \%$ & $12 \%$ & 3.55 & 1.10 \\
\hline $\begin{array}{l}\text { The county upholds virtues of trust and honesty among its } \\
\text { employees }\end{array}$ & $5 \%$ & $46 \%$ & $24 \%$ & $15 \%$ & $10 \%$ & 2.31 & 1.03 \\
\hline
\end{tabular}

Source: Researcher, (2021)

\section{Correlation Analysis on Influence of Staff Professionalism on Public Procurement Performance in County Governments in Kenya}

Table 4 shows that, staff professionalism and procurement performance were positively correlated, $r(90)=.84, p=.00$. The findings also indicated that the correlation between the two variables was statistically significant. Therefore, based on the study results the null hypothesis was rejected and the alternative hypothesis that state there exist a significant influence of staff professionalism on procurement performance in the county was adopted. This implies that an increase in staff professionalism leads to an increase in procurement performance and vice versa.

Table 4: Correlation Analysis on Influence of Staff Professionalism on Public Procurement Performance in County Governments in Kenya

\begin{tabular}{llc}
\hline & & Public Procurement performance \\
\hline \multirow{3}{*}{ Staff Professionalism } & Pearson Correlation & $.84^{* *}$ \\
& Sig. (2-tailed) & .00 \\
& $\mathrm{~N}$ & 90 \\
\hline
\end{tabular}

Source: Researcher, (2021)

The findings of this research reveal that there is a significant positive association between staff professionalism and Public procurement performance. These findings are consistent with those reported by Liu, Shi, Xue and Wang (2019) on the improvement of the public procurement performance in local governments in China. The study findings revealed that procurement officials' receiving training on how to handle operations in the local governments improved performance on the application of differentiation strategy in the course of discharging their duties and functions due to their mutual awareness of the policies and procurement programs execution.

Mrope (2017) also found similar results in a research on the impact of Staff professionalism on public performance of procurement activities in the public procurement in Tanzania. The results for procurement professionalism showed that regression analysis coefficient was 0.53 and the t-test coefficient was 4.360 which was significant $\mathrm{p}=0.000(<0.05)$. The results implied that $53 \%$ the procurement performance in the public sector could be explained by the degree to which professionalism was integrated in the execution of procurement functions and in decision making in the entity.

Another study by Odero and Ayub (2017) reported similar findings from their investigation on the effect of procurement processes on procurement overall performance in sugar manufacturing industries in Western Kenya. The study findings of regression analysis indicated staff professionalism resulted to a rise of 0.825 in procurement performance. Mesa (2018) report from an investigation on procurement practices in the judiciary law courts in Nakuru was consistent with the findings of the current research. The report indicated that, lack of staff professionalism was the main reason for the non-compliance to procurement laws. The findings also indicated that staff professionalism in contracts positively impacted on procurement performance (mean=3.967) and there was a strong relationship between procurement planning $(r=.761)$, contractual professionalism $(r=.732)$, staff competency $(r=.725)$, and procurement performance.

\section{Influence of Organizational Culture on Public Procurement Performance in County Governments in Kenya}

Table 5 presents the descriptive statistics analysis on the Influence of Organizational Culture on Public Procurement Performance. The results indicated that $17 \%$ of the respondents strongly disagreed and $8 \%$ disagreed that there were clearly defined service charter in procurement. The findings also indicated that the $69 \%$ agreed and $4 \%$ strongly agreed that there was a service charter. Only $2 \%$ of the respondents were undecided. Based on the findings, majority of the respondents supports that there exists a well-structured service charter in procurement.

Concerning whether the county upholds trustworthiness in work operations in procurement, majority of the participants representing $70 \%$ agreed and $4 \%$ strongly agreed. However, $7 \%$ of the respondents disagreed, $14 \%$ strongly disagreed while $4 \%$ remained neutral. The mean score and standard deviation was 3.4 and 1.1 respectively. The findings imply that it was not clear whether the county procurement department upholds trustworthiness in its operations. 
The question regarding whether corporate governance responsibilities in the county are highly insisted, generated results indicating that $69 \%$ of the participants disagreed and $4 \%$ strongly disagreed. The results also showed that $10 \%$ agreed, $11 \%$ strongly agreed while $6 \%$ remained neutral stand. The mean score was 2.4 with a standard deviation of 0.9 . The findings infer that corporate governance in the county is not highly encouraged.

The study also sought to find out whether there exist ethical practices in the county regarding procurement. The findings indicated that majority of the participants $(70 \%)$ disagreed and $7 \%$ strongly disagreed. Nonetheless, $7 \%$ of the participants agreed while $14 \%$ strongly agreed. Only $2 \%$ of the respondents remained neutral. The mean score was $2.3(S D=0.6)$. Based on the results, the participants disagreed on the existence of ethical practices. The participants also provided responses on whether there exist well defined policies defining the conduct of the employees dealing with procurement processes. The results revealed that $4 \%$ of the participants were undecided, while $10 \%$ disagreed and 5\% strongly disagreed. Nevertheless, $74 \%$ of the participants disagreed while $7 \%$ strongly agreed. The mean score was 3.5 with a standard deviation of 1.2 . Based on the outcomes, majority of the participants acknowledged the existence of well-structured policies that defined the procurement code of conduct while executing the procurement processes. Regarding whether the county demands team works at workplace, the findings revealed that $75 \%$ of the participants agreed and $4 \%$ strongly agreed. The outcome also indicated that $7 \%$ of the participants disagreed while $12 \%$ strongly disagreed. The mean score was $4.1(S D=1.2)$. The results infer that the county calls for team work from the employees.

Table 5: Descriptive statistics on Influence of Organizational Culture on Public Procurement Performance in County Governments in Kenya

\begin{tabular}{|c|c|c|c|c|c|c|c|}
\hline Statement & SD & D & $\mathrm{N}$ & A & SA & Mean & SD \\
\hline There exists clearly defined service charter in procurement & $17 \%$ & $8 \%$ & $2 \%$ & $69 \%$ & $4 \%$ & 3.5 & 1.2 \\
\hline The county upholds trustworthiness in work operations & $14 \%$ & $7 \%$ & $4 \%$ & $70 \%$ & $4 \%$ & 3.4 & 1.1 \\
\hline Corporate governance responsibilities in the county are highly insisted & $4 \%$ & $69 \%$ & $6 \%$ & $10 \%$ & $11 \%$ & 2.4 & 0.9 \\
\hline There exist ethical practices in the county regarding procurement & $7 \% \%$ & $70 \%$ & $2 \%$ & $7 \%$ & $14 \%$ & 2.3 & 0.6 \\
\hline $\begin{array}{l}\text { There exists well defined policies defining the conduct of the employees } \\
\text { dealing with procurement processes }\end{array}$ & $5 \%$ & $10 \%$ & $4 \%$ & $74 \%$ & $7 \%$ & 3.5 & 1.2 \\
\hline The county demands team work at workplace & $12 \%$ & $7 \%$ & $2 \%$ & $75 \%$ & $4 \%$ & 4.1 & 1.2 \\
\hline
\end{tabular}

Note. $\boldsymbol{S D}$ - Strongly Disagree, $\boldsymbol{D}$-Disagree, $\boldsymbol{N}$-Neutral, $\boldsymbol{A}$-Agree, $\boldsymbol{S A}$-Strongly Agree.

\section{Correlation Analysis on Influence of Organizational Culture on Public Procurement Performance in County Governments in Kenya}

Table 6 shows that, organizational culture influence and Public procurement performance had a significant and positive correlation $r$ $(90)=.51, p=.00$. Supported by these findings, the null hypothesis was rejected and the alternative hypothesis that states that there is a significant influence of organizational culture on procurement performance in the county was adopted. This suggests that better organizational culture is associated with better procurement performance and vice versa.

Table 6: Correlation Analysis on Influence of Organizational Culture on Public Procurement Performance in County Governments in Kenya

\begin{tabular}{llc}
\hline & & Public procurement performance \\
\hline \multirow{3}{*}{ Organizational Culture } & Pearson Correlation & $.51^{* *}$ \\
& Sig. (2-tailed) & .00 \\
& $\mathrm{~N}$ & 90 \\
\hline
\end{tabular}

The findings of this study indicated that there exists a significant and positive correlation between organizational culture and procurement performance. The findings support the results of the existing research work conducted in this area. The study findings are consistence to those reported by Porter (2019) from a study on whether organizational culture matters in supply chain development in Indonesia. The results revealed that a substantial and an elastic organizational structure, is reflected in the adhocracy cultures in an organization which lead to subsequent increase in supply chain incorporation and firm performance. The Nortel network external environment theory emphasizes that a successful organization doesn't act in a vacuum, as both internal and external organization cultural practices contributes to the overall success.

A research study by Aketch, Basheka and Bagire (2017), that was carried out in Uganda on organizational culture and performance of small and medium entrepreneurs (SMES) also reported consistence findings. It was found that organizational culture positively

This publication is licensed under Creative Commons Attribution CC BY. 
affected the efficiency of SMEs by $12.4 \%$. The organizational cultural facets that had significant influence on procurement practices were found to be the SMEs' mission and vision $(\beta=0.329$, sig=0.006) and practical involvement in their operations $(\beta=0.208$, sig=0.042). Cheruiyot (2018) examined the factors affecting effective procurement performance in different organizations in Kenya. The study results showed that organizational culture had a positive and significant impact on effective execution of the procurement functions.

\section{Influence of Institutional Framework on Public Procurement Performance in County Governments in Kenya}

From Table 7, the study examined whether the organization's bureaucratic processes are flexible enough to manage public procurement issues. Most of the participants (72.2\%) disagreed and 4.4\% strongly disagreed. Nonetheless, $6.7 \%$ of the respondents agreed and $16.7 \%$ strongly agreed. The mean score was 2.4 with a standard deviation of 1.2. Drawing from the findings, the organizational framework is not flexible enough to help manage procurement functions. The question concerning whether there is an alignment between institution's internal procurement policies and the PPAD, Act 2015, yielded findings indicating that 75\% disagreed and $6.7 \%$ strongly disagreed. The findings also showed that $1.7 \%$ agreed, $6.6 \%$ strongly agreed, while $10 \%$ of the participants remained neutral. The mean score was 2.1 with a standard deviation of 1.3. The outcomes suggest that institution's procurement policies are not consistent with the procurement Act 2015.

Regarding whether there is similarity between existing regulations on procurement and international best practices, the results indicated that most of the participants $(73.3 \%$ ) agreed and $6.7 \%$ strongly agreed. The study also found that the participants who disagreed were $3.2 \%$ while those who strongly disagreed were $6.8 \%$. The mean score was $3.5(S D=1.1)$. The study also sought to establish whether the internal operation policy such as centralization of procurement decisions promotes better procurement. The findings showed that most of the participants (68\%) were undecided, while $22 \%$ disagreed and 5\% strongly disagreed. However, $3 \%$ of the participants agreed while $2 \%$ strongly agreed. The mean score and standard deviation were 3.1 and 1.2 respectively. The findings imply that the participants were uncertain on whether the internal procurement policy promoted procurement function.

The participants also gave responses on whether the county has aligned its organizational structures to support best procurement activities. The findings indicated that $70 \%$ of the respondents disagreed and $7 \%$ strongly disagreed. The findings also showed that $17 \%$ of the participants strongly agreed while $7 \%$ remained neutral. The mean score was 2.2 with a standard deviation of 1.0 . Based on the findings, the majority of the respondents didn't support that the idea that the county has aligned its organizational structures for best procurement practices.

Table 7: Descriptive statistics on Influence of Institutional Framework on Public Procurement Performance in County Governments in Kenya

\begin{tabular}{|c|c|c|c|c|c|c|c|}
\hline Statement & SD & $\mathrm{D}$ & $\mathrm{N}$ & $\mathrm{A}$ & SA & Mean & SD \\
\hline $\begin{array}{l}\text { The organization's bureaucratic set up is flexible to manage } \\
\text { public procurement issues }\end{array}$ & $4.4 \%$ & $72.2 \%$ & - & $6.7 \%$ & $16.7 \%$ & 2.4 & 1.2 \\
\hline $\begin{array}{l}\text { There is an alignment between institution's internal procurement } \\
\text { policies and the PPAD, Act } 2015\end{array}$ & $6.7 \%$ & $75 \%$ & $10 \%$ & $1.7 \%$ & $6.6 \%$ & 2.1 & 1.3 \\
\hline $\begin{array}{l}\text { There is similarity between existing regulations on procurement } \\
\text { and international best practices }\end{array}$ & $6.8 \%$ & $3.2 \%$ & $10 \%$ & $73.3 \%$ & $6.7 \%$ & 3.5 & 1.1 \\
\hline $\begin{array}{l}\text { Internal operation policies such as centralization of procurement } \\
\text { decisions promotes better procurement }\end{array}$ & $5 \%$ & $22 \%$ & $68 \%$ & $3 \%$ & $2 \%$ & 3.1 & 1.2 \\
\hline $\begin{array}{l}\text { The county has aligned its organizational structures to support } \\
\text { best procurement activities }\end{array}$ & $7 \%$ & $70 \%$ & $7 \%$ & - & $17 \%$ & 2.2 & 1.0 \\
\hline
\end{tabular}

Note. $\boldsymbol{S D}$ - Strongly Disagree, $\boldsymbol{D}$-Disagree, $\boldsymbol{N}$-Neutral, $\boldsymbol{A}$-Agree, $\boldsymbol{S} \boldsymbol{A}$-Strongly Agree

Correlation Analysis on Influence of Institutional Framework on Public Procurement Performance in County Governments in Kenya

Table 8, indicates that, institutional framework and procurement performance had a significant and positive correlation $r(90)=.77, p$ $=.00$. Based on the results, the null hypothesis was rejected and the alternative hypothesis that states that there is no significant influence of institutional framework on procurement performance in county governments was adopted. This infers that an increased institutional framework influence was associated with a subsequent increase procurement performance.

Table 8: Correlation Analysis on Influence of Institutional Framework on Public Procurement Performance in County Governments in Kenya

Public Procurement performance

\begin{tabular}{lll}
\hline Institutional Framework & Pearson Correlation & $.77^{* *}$
\end{tabular}

This publication is licensed under Creative Commons Attribution CC BY.

http://dx.doi.org/10.29322/IJSRP.11.10.2021.p11881

WwW.ijsrp.org 


\section{Sig. (2-tailed)}

$\mathrm{N}$
.00

90

Source: Researcher, (2021)

The findings of this research indicates that there a significant and positive association between institutional framework and procurement performance. An increase in institutional framework influence resulted into a proportionate increase in procurement performance. Patrucco, Walker, Luzzin and Ronchi (2019) research findings indicated that the way public procurement functions are organized and executed influence its performance. The study also reported that the organizational structure, suitability and potential for redesign is usually depend on contextual factors such goals, government decision, regulation, and the success of the existing framework. A study by Hamza, Gerbi and Ali (2017) reported similar findings in their study that focused on factors influencing procurement performance in Awassa Textile Share Company. The research findings indicated that top management and organizational structure influenced resource allocation and execution of procurement functions. This also impacted on staff competency in relation to procurement negotiation skills, motivation, creativity, interpersonal and deployment. The institutional theory argues that procurement performance can be determined by the existing structural framework compliance and top management ability to promote organizations culture, rules, regulations and norms around them.

\section{Influence of Top Management Support on Public Procurement Performance in County Governments in Kenya}

In the first question, the study sought to establish whether the top management in the county offers financial support to procurement activities. The findings indicated that $4 \%$ of the participants disagreed and 10\% strongly disagreed that top management offered financial support. The findings also indicated that $69 \%$ strongly agreed, $7 \%$ agreed while $10 \%$ were undecided. The mean score was 4.3 with a standard deviation of 1.3. Based on the outcome, majority of the participants supported that the top management offered financial support to the procurement's functions.

The question regarding whether there is political goodwill in the county operations yielded findings indicating that most of the participants representing $70 \%$ disagreed and $6.7 \%$ strongly disagreed. The results also revealed that $20 \%$ were neutral while $2.4 \%$ of the participants disagreed. The mean score and the standard deviation were 2.4 and 1.2 respectively. Generally, the results showed that there is no political good will in the procurement operations in the county. Concerning whether the county leadership leads by example in adhering to procurement regulation, most of the participants (68\%) disagreed and $16 \%$ strongly disagreed. However, $5 \%$ agreed whereas $3 \%$ strongly agreed. Only $8 \%$ of the participants were undecided. The mean score was $2.3(S D=1.3)$. According to the findings, the county leadership does not lead by example in adhering to set regulations. The researcher also probed whether the county leadership leads by example in punishing those who break procurement regulations. The findings showed that majority of the participants (56\%) disagreed whereas $12 \%$ strongly disagreed. Nonetheless, $22 \%$ of the respondents were undecided, $7 \%$ agreed and $3 \%$ strongly agreed. The mean score was 2.1 with a standard deviation of 1.1 . Generally, the outcome showed that leadership is not leading by example in disciplining those who break procurement law. With regard to the question on whether the top management in the county comes up with supportive policies regarding procurement, the results obtained showed that $20 \%$ disagreed, $3.4 \%$ strongly disagreed while $68.9 \%$ of the participants were undecided. The findings also indicated that $2 \%$ agreed whereas $3.3 \%$ of the respondent strongly agreed. The mean score and standard deviation was 3.3 and 1.4 respectively. The findings revealed that most of the participants were uncertain on whether the top management comes up with supportive policies on procurement.

Table 9: Descriptive statistics on Influence of Top Management Support on Public Procurement Performance in County Governments in Kenya

\begin{tabular}{|c|c|c|c|c|c|c|c|}
\hline Statement & SD & $\mathrm{D}$ & $\mathrm{N}$ & $\mathrm{A}$ & SA & Mean & SD \\
\hline $\begin{array}{l}\text { The top management in the county offers financial } \\
\text { support to procurement activities }\end{array}$ & $10 \%$ & $4 \%$ & $10 \%$ & $7 \%$ & $69 \%$ & 4.3 & 1.3 \\
\hline There is political goodwill in the county operations & $6.7 \%$ & $70 \%$ & $20 \%$ & $3.3 \%$ & - & 2.4 & 1.2 \\
\hline $\begin{array}{l}\text { In adhering to procurement regulations, the county } \\
\text { leadership leads by example }\end{array}$ & $16 \%$ & $68 \%$ & $8 \%$ & $5 \%$ & $3 \%$ & 2.3 & 1.3 \\
\hline $\begin{array}{l}\text { In punishing those who break procurement regulations, } \\
\text { the county leadership leads by example }\end{array}$ & $12 \%$ & $56 \%$ & $22 \%$ & $7 \%$ & $3 \%$ & 2.1 & 1.1 \\
\hline $\begin{array}{l}\text { The top management in the county comes up with } \\
\text { supportive policies regarding procurement }\end{array}$ & $3.4 \%$ & $20 \%$ & $68.9 \%$ & $5.7 \%$ & $2 \%$ & 3.3 & 1.4 \\
\hline
\end{tabular}

Note. $\boldsymbol{S D}$ - Strongly Disagree, $\boldsymbol{D}$-Disagree, $\boldsymbol{N}$-Neutral, $\boldsymbol{A}$-Agree, $\boldsymbol{S A}$-Strongly Agree 


\section{Correlation Analysis on Influence of Top Management Support on Public Procurement Performance in County Governments} in Kenya

Table 10, indicate that, top management and procurement performance are positively correlated, $r(90)=.87, p=.00$. The result also shows that the correlation between top management support and procurement performance was statistically significant. Therefore, based on the study findings the null hypothesis was rejected and alternative hypothesis which stated that there exists a significant influence of top management support on procurement performance in county governments was adopted.

Table 10: Correlation Analysis on Influence of Top Management Support on Public Procurement Performance in County Governments in Kenya

Public Procurement performance

Pearson Correlation

Sig. (2-tailed)

$\mathrm{N}$

$.87^{* *}$

.00

90

Source: Researcher, (2021)

The findings of the study indicate that there was a significant and positive correlation between top management support and procurement performance. These results are consistent with the findings from past research work conducted in this area. A research study by Hamza et al. (2018) focused on examining the moderating effect of top management on cloud-enabled technology integration on supply-chain operations in public corporation in US. The findings revealed that top management support of procurement processes moderated the relationship between staff, supplier and internal functions of the supply-chain performance.

Milanzi and Bond-Barnard (2017) reported similar findings from an investigation on the impact of procurement central management in South African mining operations. The study findings established that management team is critical in any organization as it significantly influences procurement performance. Procurement management plays important roles such as financial planning, monitoring, decision-making and financial control which impact on the performance of the procurement and organization overall success.

In another study, Sindiga (2019) examined the effects of procurement management functions on performance of construction firms in Nairobi. The findings indicated that management has a positive and significant effect on the firms ' performance. The research also reported that management support on automation of the procurement inventory processes increased its efficiency and performance while providing the management with information to enhance their operations to minimize error and enhance sustainable performance.

Ndung'u, Were and Mwangangi (2020) who explored the effects of top management support on the compliance level of the procurement to the regulatory requirements in public universities. The findings revealed that top management significantly influenced the procurement regulatory compliance level. The study also reported that motivation of employees can be used as an approach to combating personal interest in their line of duty.

\section{Regression Model summary for independent variables}

Table 11 shows the Regression model summary for independent variables.

Table 11: Regression Model Summary

\begin{tabular}{lccccc}
\hline Model & $\mathrm{R}$ & R Square & Adjusted R Square & Std. Error of the Estimate & Durbin-Watson \\
\hline 1 & $.88^{\mathrm{a}}$ & .79 & .78 & 3.17 & 1.83 \\
\hline
\end{tabular}

a. Predictors: (Constant), Top Management Support, Staff Professionalism, Organizational Culture

b. Dependent Variable: Procurement performance

Table 11 presents the model which shows that the independent variables (top management support, staff professionalism, organizational culture and institutional framework) accounted for $79 \%$ in procurement performance as indicated by adjusted R square 
(.79). This implies that procurement (dependent variable) was highly predicted by top management support, staff professionalism, and organizational culture.

Table 12: Analysis of Variance (ANOVA)

\begin{tabular}{llccccc}
\hline Model & & Sum of Squares & df & Mean Square & F & Sig. \\
\hline \multirow{2}{*}{1} & Regression & 3223.08 & 3 & 1074.36 & 106.90 & $.00^{\mathrm{b}}$ \\
& Residual & 864.30 & 86 & 10.05 & & \\
& Total & 4087.38 & 89 & & & \\
\hline
\end{tabular}

Source: Field Data (2021)

Table 12 shows that top management support, staff professionalism, and organizational culture significantly predict procurement performance $(F(3,223)=106.90, p<05)$.

Table 13: Coefficients' Relationship between the independent variables and Public Procurement Performance in County Governments in Kenya

\begin{tabular}{|c|c|c|c|c|}
\hline \multirow[t]{2}{*}{ Model } & \multicolumn{2}{|l|}{$\begin{array}{l}\text { Unstandardized } \\
\text { Coefficients }\end{array}$} & $\begin{array}{l}\text { Standardized } \\
\text { Coefficients }\end{array}$ & \multirow[t]{2}{*}{ Sig } \\
\hline & $\mathrm{B}$ & Std. Error & Beta & \\
\hline (Constant) & -1.567 & 1.274 & & .00 \\
\hline Staff Professionalism & .331 & .160 & 247 & .00 \\
\hline Organizational Culture & .158 & .144 & .160 & .00 \\
\hline Top Management Support & .574 & .174 & .506 & .00 \\
\hline Institutional Framework & .212 & .632 & .481 & .00 \\
\hline
\end{tabular}

a. Dependent Variable: Public Procurement Performance

Table 13 indicates that top management support, staff professionalism, organizational culture and institutional framework had a statistically significant regression coefficients as signified by their $\mathrm{p}$ values $(\mathrm{p}<.05)$. The findings indicate that top management support had the highest predictive index on procurement performance $(.574, p<.00)$, followed by staff professionalism $(.331, \mathrm{p}<.00)$, institutional framework $(.212, p<.00)$ and lastly by organizational culture $(.158, p<.00)$.

Regression Model: $\mathrm{Y}=\beta 0+\beta 1 \mathrm{X} 1+\beta 2 \mathrm{X} 2+\beta 3 \mathrm{X} 3+\beta 4 \mathrm{X} 4+\varepsilon ;$ Will be represented as;

$Y=-1.567+0.331 X_{1}+0.158 X_{2}+0.574 X_{3}+0.212 X_{4}$

Where $\mathrm{Y}=$ predicted Public procurement performance, $\mathrm{X}_{1}=$ staff professionalism; $\mathrm{X}_{2}=$ organizational culture; $\mathrm{X}_{3}=$ top management support; $\mathrm{X}_{4}=$ institutional framework.

The results infer that a unit increase in staff professionalism resulted to 0.331 change in procurement performance and vice versa. Additionally, the results show that a unit change in organization culture could result to 0.158 change in procurement performance, whereas a unit change in top management support could lead to 0.574 change in procurement performance and a unit change in institutional framework resulted to 0.212 change in procurement performance.

\subsection{Summary of the findings.}

The findings indicated that top management support, staff professionalism, organizational culture and institutional framework significantly predict procurement performance $(F(3,223)=106.90, p<05)$. The study established that top management support had the highest predictive weight on procurement performance $(.574, p<.00)$, followed by staff professionalism $(.331, \mathrm{p}<.00)$, institutional framework $(212, p<.00)$, and organizational culture $(.158, p<.00)$. The $\mathrm{p}$ value for all independent variables was < .005 which implies that they were all statistically significant. The findings also showed that top management support, staff professionalism, and organizational culture explained $79 \%$ variance in procurement performance; this infers that the three independent variables had a pretty high influence on procurement performance.

In the first objective, the study sought to establish the influence of staff professionalism on procurement performance in County Governments in Kenya. The research hypothesis established that there was a positive significant relationship between staff professionalism and public procurement performance with $\mathrm{r}(90)=.84, \mathrm{p}=.00$.

Concerning the second objective, the study aimed to determine the influence of organizational culture on procurement performance. The hypothesis on the correlation between organizational culture and procurement performance was analyzed using Pearson 
correlation. The results from correlation analysis indicated that there was a significant positive relationship between organizational culture and procurement performance.

In the third objective, the study sought to establish the influence of institutional framework on procurement performance. The results from the correlation analysis showed that there was a significant positive correlation between institutional framework and procurement performance. The fourth objective of this study was to determine whether there was a significant influence of top management support on procurement performance. The study found that top management supported procurement services. The research hypothesis on the relationship between top management support and procurement performance was tested using Pearson correlation analysis. The outcome showed that there was a significant and positive correlation between top management support and procurement performance.

\subsection{Conclusion}

In the first objective, the study sought to find out the influence of staff professionalism on procurement performance. The findings indicated that staff professionalism had a positive and significant influence on procurement performance. The findings infer that an increase in staff professionalism resulted to a subsequent increase in procurement performance.

In regard to the second objective on influence of organizational culture on procurement performance, the findings indicated that they were positively and significantly correlated. Higher scores on organizational culture result to higher scores on procurement performance and vice versa.

In the third objective on the influence of institutional framework on procurement performance, the study findings indicated there was positive and significant correlation between the two variables. This implies that an increase in institutional framework score resulted to a proportionate increase in procurement performance and vice versa. Therefore, the county government should have a sound and operational framework to enhance procurement performance.

On influence of top management support on procurement performance, the study findings revealed that there was a positive significant correlation between the two variables. The results suggest that an increase in top management support score results to a subsequent increase in procurement performance score and vice versa.

\subsection{Recommendations}

This research was conducted in Garissa County procurement and may be limited in generalization due to cultural and geographical differences. Therefore, the researcher recommends a replication of this study in other counties for more comprehensive findings to address the differences and confirm the findings of this study.

The study employed only four variables out of a pool of different factors that influence procurement performance in the counties. Therefore, further research using different variables is should be conducted to provide a wide picture and more comprehensive findings.

The study employed only correlation analysis methods in establishing the relationship between the variables of the study. Further research is recommended using different analytical techniques to provide detailed results and to confirm the findings on the influence of institutional factors on public procurement performance in county governments in Kenya.

\section{References}

Abdumlingo. H, \& Mugambi. M. F (2014). Challenges of managing devolved funds in the delivery of services: A case study of Mombasa County. International Journal of Research in Commerce \& Management; 5(5), 78-112.

Adejimi, A., Oyediran, O. S., \& Ogunsanmi, E. B. (2010). Employing qualitatively enriched semi structured questionnaire in evaluating ICT impact on Nigerian 'construction chain integration'. The Built \& Human Environment Review, 3(1), 49-62.

Aketch, E., Basheka, B. C., \& Bagire, V. (2017). Organizational culture and performance of SMEs in Uganda: a case study of hotel sector. International Journal of Technology and Management, 2(1), 15-15.

Allred, S. B., \& Ross-Davis, A. (2011). The drop-off and pick-up method: An approach to reduce nonresponse bias in natural resource surveys. Small-Scale Forestry, 10(3), 305-318.

Amayi, F. K., \& Ngugi, G. K. (2013). Determinants of public procurement performance in Kenya: Case Ministry of Environment, Water and Natural Resources. International Journal of Social Sciences and Entrepreneurship, 1(5), 647-667. 
Amemba, C. S., Nyaboke, P. G., Osoro, A., \& Mburu, N. (2013). Challenges affecting public procurement performance process in Kenya. International Journal of Research in Management, 3(4), 41-55.

Babin, B. (2010). The essence of research methodology: A concise guide for master and PhD students in management science. Springer Science \& Business Media.

Bakir, S., Khan, S., Ahsan, K., \& Rahman, S. (2018). Exploring the critical determinants of environmentally oriented public procurement using the DEMATEL method. Journal of Environmental Management, 225, 325-335.

Basheka, B. C., \& Bisangabasija, E. (2009). Determinants of Unethical Public Procurement in Local Governments Systems of Uganda: A Case Study. International Journal of Procurement Management, 91-104.

Blumberg, B. F., Cooper, D. R., \& Schindler, P. S. (2014). Business Research Methods.

Bosio, E., Djankov, S., Glaeser, E. L., \& Shleifer, A. (20I8). Public procurement in law and practice (No. w27188). National Bureau of Economic Research.

Brace, K. (2013). Handbook of survey research. Academic Press.

Broms, R., Dahlström, C., \& Fazekas, M. (2019). Political competition and public procurement outcomes. Comparative Political Studies, 52(9), 1259-1292.

Burns, N., \& Grove, S. K. (2010). Understanding Nursing Research-eBook: Building an Evidence-Based Practice. Elsevier Health Sciences.

Cheruiyot, B. K. (2018). Factors Influencing Effective Implementation of Procurement Practices In Non-Governmental Organizations: A Case of Caritas Rumbek. Journal of International Business, Innovation and Strategic Management, 1(1), $130-148$.

DiMaggio, Paul J. \& Powell, Walter W. (1991)‘Introduction'. In P. J. DiMaggio and W. Powell (eds.) 'The New Institutionalism and Organizational Analysis. Chicago: University of Chicago Press.

Fazekas, M., \& Kocsis, G. (2018). Uncovering high-level corruption: cross-national objective corruption risk indicators using public procurement data. British Journal of Political Science, 50(1), 155-164.

Garg, G., \& Kothari, C. R. (2014). Research Methodology. Methods and Techniques.New Age International Publishers. New Delhi110002

Gatere, B. C. \& Shale, N. I. (2014). Challenges affecting the implementation of access to government procurement opportunities for special interest groups in Kenya: A case of Nairobi County. International Journal of Social Sciences and Entrepreneurship, 1 (12), 831-847.

Getange, B. N. (2020). Transformational leadership, organizational culture, regulatory framework and performance of state corporations in kenya (Doctoral Dissertation, MUA)

Gorsira, M., Denkers, A., \& Huisman, W. (2018). Both sides of the coin: Motives for corruption among public officials and business employees. Journal of Business Ethics, 151(1), 179-194.

Grandia, J., \& Voncken, D. (2019). Sustainable public procurement: the impact of ability, motivation, and opportunity on the implementation of different types of sustainable public procurement. Sustainability, 11(19), 5215.

Hamza, S. B., Gerbi, A., \& Ali, S. H. (2017). Factors affecting procurement performance in the case of awassa textile share company. Global Journal of Management and Business Research., 4(3), 44.

Hossain, M. (2017). Factors affecting procurement process efficiency of British American Tobacco Bangladesh. International Journal of Business and Commerce, 8(5), 12-34.

Ikumu, B.C., Iravo, A.M. \& Ondabu, I.T. (2014). Factors Influencing Procurement Performance In The Kenyan Public Sector: Case Study Of The State Law Office. International Journal of Innovation and Applied Studies, 6(7), 23-45. 
Kakwezi, P., \& Nyeko, S. (2019). Procurement processes and performance: Efficiency and effectiveness of the procurement function. International Journal of Social Sciences Management and Entrepreneurship (IJSSME), 3(1), 69-84.

Kinuthia, D. W., \& Abdallah, I. A. (2015). Effects of Information Communication Technology Adoption on Procurement Process in Kenya's Oil Industry: A Survey of Total Kenya Limited Mombasa County. International Journal of Management and Commerce Innovations, 2(2), 56-123.

Kioko, N. J., \& Were, S. (2014). Factors affecting efficiency of the procurement function at the public institutions in Kenya, A case of Supplies Branch in Nairobi. International Journal of Business \& Law Research, 2(2), 1-14.

Lara-Alecio, R., Guerrero, C., \& Lopez, T. (2019). A process for establishing and maintaining inter-rater reliability for two observation instruments as a fidelity of implementation measure: a large-scale randomized controlled trial perspective. Studies in Educational Evaluation, 62, 18-29.

Larbi, B. O., Baiden, B. K., \& Agyekum, K. (2019). Compliance with transparency provisions in the Public Procurement Act, 2003 (Act 663). International Journal of Procurement Management, 12(1), 112-133.

Liu, J., Shi, B., Xue, J., \& Wang, Q. (2019). Improving the green public procurement performance of Chinese local governments: From the perspective of officials' knowledge. Journal of Purchasing and Supply Management, 25(3), 100501.

Manyenze, N. (2013). Procurement performance in the public universities in Kenya (Doctoral dissertation), University of Nairobi.

March, J. G.,\& Oslen, J.P. (1989). Rediscovering institutions: “Organizational Basis of politics” pp.161

Matano, F., Musau, E., \& Nyaboga, Y. B. (2018). Effects of e-procurement implementation practices on procurement of goods, works and services in the national youth service, Nairobi City County. International Academic Journal of Procurement and Supply Chain Management, 3(2), 63-82.

Melanie, H. \& Eriika,P. (2013). Longitudinal research in organizations: an introduction. Me Hassett, E. \& Paavilainen-Mäntymäki (Eds.). Handbook of Methods in longitudinal research and business organization studies, 1-22.

Mesa, R. N. (2018). Determinants of procurement performance in judiciary department at the Nakuru Law Courts, Kenya (Doctoral dissertation), JKUAT.

Milanzi, M., \& Bond-Barnard, T. (2017). Exploring the Effects of Centralised Procurement on Projects in South African Matrix Mining Organisations. In Project Management Institute Australia Conference, 3, 1-22.

Mrope, N. P. (2017). The effect of professionalism on performance of procurement function in the public sector: experience from the Tanzanian public entities. International Journal of Business and Management Review, 5(6), 48-59.

Mugenda, O. M., \& Mugenda, A. G. (2013). Research methodology sample for social researches. International Research Journal, 16(4), 331.

Musau, E. G. (2015). Environmental Factors Affecting Procurement Performance in County Governments: A Case of Uasin Gishu County. International Journal of Business and Management Invention, 4(1), 50-59.

Mutangili, S. K. (2019). Corruption in Public Procurement in Kenya: Causes, Consequences, Challenges and Cures. Journal of Procurement \& Supply Chain, 3(1), 63-72.

Ndung'u, N., Were, S., \& Mwangangi, P. (2020). Influence of top management support on procurement regulatory compliance level in public universities in Kenya. International Journal of Supply Chain and Logistics, 4(1), 1-12.

Nyoike, S. (2019). Public Procurement Reforms in Kenya: a Quest for Equity and Fairness (Doctoral dissertation), University of Nairobi.

Odero, J. A., \& Ayub, S. E. (2017). Effect of procurement practices on procurement performance of public sugar manufacturing firms in Western Kenya. International Journal of Management Research and Reviews, 7(4), 521.

Onyango, G. (2020). Whistleblowing behaviours and anti-corruption approaches in public administration in Kenya. Economic and Political Studies, 1-25. 
Owiti, E. O. (2018). Factors Affecting Implementation of Preference and Reservation Procurement Policy in State Corporations in Kenya: A Case of Kenya Railways Corporation. Journal of International Business, Innovation and Strategic Management, 1(1), 43-63.

Patrucco, A. S., Walker, H., Luzzini, D., \& Ronchi, S. (2019). Which shape fits best? Designing the organizational to enhance local government procurement functions. Journal of Purchasing and Supply Management, 25(3), 100504.

Porter, M. (2019). Supply chain integration: Does organizational culture matter?. Operations and Supply Chain Management: An International Journal, 12(1), 49-59.

Pujoyono, S., Akbar, B., Djaenuri, A., \& Ilham, M. (2019). Effects of Leadership, Organizational Culture \& Competence on Procurement of Government Goods and Services at the Directorate of Prevention and Control of Direct Communicable Diseases of the Indonesian Republic Ministry of Health. International Journal of Science and Society, 1(2), 71-82.

Shee, H., Miah, S. J., Fairfield, L., \& Pujawan, N. (2018). The impact of cloud-enabled process integration on supply chain performance and firm sustainability: the moderating role of top management. Supply Chain Management: An International Journal. 2, 234

Sindiga, L. K., Paul, S. N., \& Mbura, L. K. (2019). Influence of procurement management practices on performance of construction firms in Nairobi County, Kenya. International Academic Journal of Procurement and Supply Chain Management, 3(1), 143163.

Sinha, A., Gupta, M., Shahbaz, M., \& Sengupta, T. (2019). Impact of corruption in public sector on environmental quality: Implications for sustainability in BRICS and next 11 countries. Journal of Cleaner Production, 232, 1379-1393.

Smith, J. A. (2015). Interpretative phenomenological analysis as a useful methodology for research on the lived experience of pain. British Journal of Pain, 9(1), 41-42.

Soomro, B. A., \& Shah, N. (2019). Determining the impact of entrepreneurial orientation and organizational culture on job satisfaction, organizational commitment, and employee's performance. South Asian Journal of Business Studies.2(1), 122456.

Srivastava, S. K., \& Agrahari, A. (2017). Benchmarking approach to improve public procurement process. Samir K Srivastava and Amit Agrahari, Benchmarking approach to improve public procurement process. Economic and Political Weekly, 52(20), 5867.

Sun, T., \& Sales, L. J. (2018). Predicting public procurement irregularity: An application of neural networks. Journal of Emerging Technologies in Accounting, 15(1), 141-154.

Thairu, J., \& Chirchir, M. (2016). Implementation of the Youth Preference and Reservations Policy in Public Procurement: The Case of State Owned Enterprises in Nairobi. International Journal of Supply Chain Management, 1(1), 1-18.

Thumbi, I. N., \& Mutiso, J. M. (2018). Influence of Procurement Process Audit on Procurement Performance in Public Health Facilities in Kiambu County, Kenya. International Journal of Social Sciences and Information Technology, 6(10), 115-164.

Toroitich, J. K., Mburugu, K. N., \& Waweru, L. (2017). Influence of employee competence on the implementation of electronic procurement in the selected county governments in Kenya. International Academic. Journal of Human Resource and Business Administration, 2(3), 242-254.

Transparency International (2013). Corruption Perception Index [Online]. Available at http://www.transparency.org

Upagade, V., \& Shende, A. (2012). Research methodology. Chand \& Company Ltd. New Delhi, India.

Vilcu, I., Mbuthia, B., \& Ravishankar, N. (2020). Purchasing reforms and tracking health resources, Kenya. Bulletin of the World Health Organization, 98(2), 126.

Wilson, J. (2014). Essentials of business research: A guide to doing your research project. Sage.

World Bank. (2020). Systematic Country Diagnostic: Kenya.: Procurement Service Unit, government levels:Nairobi, Kenya. 
International Journal of Scientific and Research Publications, Volume 11, Issue 10, October 2021 